\title{
As práticas de letramento matemático digital e o papel mediador das tecnologias digitais: uma experiência com o software superlogo na educação básica
}

\section{The practices of digital mathematical lettering and the mediating role of digital technologies: an experience with the superlogue software in basic education}

\author{
Francislaine Ávila de Souza ${ }^{1}$ \\ José Antônio Araújo Andrade ${ }^{2}$ \\ Francine de Paulo Martins ${ }^{3}$
}

\begin{abstract}
Resumo
$\mathrm{O}$ artigo em tela refere-se a um recorte de uma pesquisa desenvolvida no âmbito do Mestrado Profissional em Educação, cujo objetivo foi o de analisar as potencialidades do ambiente computacional Logo em práticas de letramento matemático digital no desenvolvimento do pensamento algébrico. Os dados foram gerados a partir de tarefas desenvolvidas com estudantes do quinto ano do Ensino Fundamental de uma escola pública do interior de Minas Gerais. Para fundamentação teórica, foram utilizados como aporte teórico autores que discutem sobre as tecnologias digitais e sobre o letramento matemático e letramento digital com foco em Soares (2002), Ribeiro e Coscarelli (2017), Street (2004), Borba (2001) e Mendes (2007). Obteve-se como resultado a compreensão de que o uso das tecnologias digitais potencializa o processo de ensino e de aprendizagem, uma vez que o estudante é colocado frente a sua realidade social, pois atualmente a tecnologia digital faz parte da história e do contexto cultural dos sujeitos, e essa utilização da tecnologia digital, e de outras mídias, e a intencionalidade em que a situação desencadeadora de aprendizagem foi elaborada permitiu que fossem mobilizados os conhecimentos cotidianos, os conhecimentos matemáticos e os conhecimentos digitais que eles já possuíam e somando-se àqueles que eles adquiram durante a tarefa, atingindo aos objetivos de aprendizagem.
\end{abstract}

Palavras-chave: Educação Matemática; Letramento Matemático Digital; Educação Básica.

\begin{abstract}
The article in question refers to an excerpt from a research developed within the scope of the Professional Master's in Education, whose objective was to analyze the potential of the computational environment Logo in digital mathematical literacy practices in the development of algebraic thinking. The data were generated from tasks developed with

\footnotetext{
${ }^{1}$ Mestre em Educação, Universidade Federal de Lavras, Lavras. Minas Gerais, Brasil. E-mail: francislaineavila@hotmail.com.

${ }^{2}$ Doutor em Educação, Universidade Federal de Lavras, Lavras. Minas Gerais, Brasil. E-mail: joseaaa@ufla.br.

${ }^{3}$ Doutora em Educação, Universidade Federal de Lavras, Lavras. Minas Gerais, Brasil. E-mail:

francine.lima@ufla.br.
} 
students in the fifth year of elementary school at a public school in the interior of Minas Gerais. For theoretical foundation, authors who discuss digital technologies and mathematical literacy and digital literacy with a focus on Soares (2002), Ribeiro and Coscarelli (2017), Street (2004), Borba (2001) and Mendes (2007) were used as theoretical input. As a result, it was obtained the understanding that the use of digital technologies enhances the teaching and learning process, since the student is placed in front of their social reality, as currently digital technology is part of the history and cultural context of the students. subjects, and this use of digital technology, and other media, and the intentionality in which the situation triggering the learning was elaborated allowed the daily knowledge, mathematical knowledge and digital knowledge they already had to be mobilized and added to those that they acquire during the task, reaching the learning objectives.

Keywords: Mathematical Education; Digital Mathematical Literacy; Basic education.

\section{Introdução}

O ensino da Matemática na Educação Básica é de suma importância para os sujeitos que farão uso dela em vários momentos ao longo de toda a sua vida, desenvolvendo o pensamento lógico e permitindo a construção do conhecimento em diversas áreas.

$\mathrm{O}$ artigo em tela refere-se a um recorte de uma pesquisa desenvolvida para a consecução do trabalho final no âmbito do Mestrado Profissional em Educação da Universidade Federal de Lavras (UFLA) que teve como título "O desenvolvimento do pensamento algébrico mediado por tecnologias digitais nos primeiros anos da educação básica". A pesquisa, de modo geral, tratou sobre o desenvolvimento do pensamento algébrico em situações mediadas por tecnologias digitais, discutindo também sobre as práticas de letramento matemático e letramento matemático digital, conceito que ainda é recente no campo da educação. Como produto final, elaborou-se e desenvolveu-se um conjunto de situações desencadeadoras de aprendizagem (SDA) que possibilitassem ao profissional da Educação estabelecer uma discussão a respeito do pensamento algébrico e suas características, nos anos iniciais do Ensino Fundamental. O recorte ao qual se reporta este artigo é referente a uma das SDA em que se utiliza como instrumento de mediação a linguagem de programação computacional SuperLogo.

Nesse sentido, o objetivo deste artigo é analisar as potencialidades do ambiente computacional Logo em práticas de letramento matemático digital no desenvolvimento do pensamento algébrico. 
Desse modo, a discussão surge a partir da análise, pautada na perspectiva históricocultural, de uma tarefa, selecionada para discussão nesse artigo, realizada por meio do software SuperLogo, desenvolvido pelo matemático Seymour Papert, que trata de uma linguagem de programação, na qual o estudante precisa pensar para executar os comandos de forma correta. Os sujeitos da referida pesquisa são estudantes do $5^{\circ}$ ano do Ensino Fundamental de uma escola da rede pública, localizada em Minas Gerais, e as tarefas foram realizadas no laboratório de informática da própria instituição.

O presente texto encontra-se organizado de modo que, inicialmente, tece-se uma discussão acerca do conceito de letramento, bem como a busca pelo conceito de letramento matemático digital e, por fim, apresenta-se uma análise sobre uma tarefa desenvolvida em sala de aula, visando desenvolver práticas de letramento matemático digital.

\section{Letramento: algumas aproximações}

Inicialmente, antes de buscar compreensões acerca do letramento matemático digital e uma possível conceituação do mesmo, é preciso conhecer a origem e a definição da palavra letramento, buscando compreendê-la inserida na educação. O termo letramento, definido na perspectiva pedagógica, é “o resultado da ação de ensinar ou de aprender a ler e escrever: o estado ou condição que adquire um grupo social ou um indivíduo como consequência de terse apropriado da escrita" (SOARES, 2016, p. 18).

Esse vocábulo não pertencia ao vocabulário da educação brasileira até meados de 1980 e somente a partir desse período, é que alguns autores começaram a fazer uso dela para designar algo que até então não se tinha uma dada nomeação. Discorrendo sobre essa temática, Soares (2002) pontua que a introdução do termo letramento é recente na área da educação, o que ocasiona a não existência de um conceito preciso que possa ser usado, pois depende da ênfase dada para a caracterização do fenômeno observado.

A palavra letramento foi traduzida literalmente da palavra inglesa, de base latim, literacy, definida como o estado ou condição que assume aquele que aprende a ler e a escrever. Soares (2012, p. 17) amplia a definição do conceito quando aponta que, "implícita nesse conceito está à ideia de que a escrita traz consequências sociais, culturais, políticas, 
econômicas, cognitivas, linguísticas, quer para o grupo social em que seja introduzida, quer para o indivíduo que aprenda a usá-la".

Diante do exposto, observa-se que nos primeiros estudos realizados sobre a definição de letramento, o termo era entendido como alfabetismo, ou seja, o que é definido como estado ou qualidade de alfabetizado, ou sinônimo de alfabetização, como aponta Soares (2016). Posteriormente, com os avanços das pesquisas, considerou-se que embora sejam indissociáveis na prática escolar, letramento e alfabetização apresentam, no Brasil, definições que os tornam diferentes das definições citadas anteriormente, uma vez que com o surgimento de novas ideias, novos fatos e novas maneiras de compreender os fenômenos, surge também a necessidade de novas definições, ou até mesmo novos termos para designar as mudanças percebidas de acordo com a realidade social e cultural. A partir desse contexto surgiu, então, o termo letramento.

Alguns estudos apontam que em alguns países desenvolvidos a avaliação do nível de letramento já é utilizada, uma vez que vem sendo considerada "a verificação da capacidade de usar a leitura e a escrita para uma prática social" (SOARES, 2016, p. 21).

Nesse sentido, no Brasil, alguns autores já discutem a importância do termo inserido no campo pedagógico e demonstram que, atualmente, discorrer sobre letramento no contexto escolar permite aos educadores promoverem práticas que possibilitem ao estudante, além saber ler e escrever, conhecer e fazer uso dos conteúdos aprendidos na escola e em diferentes contextos sociais. Portanto, é necessário considerar que as discussões sobre o letramento surgem da ampliação de uma visão individual que os processos de alfabetização apresentavam, buscando entender qual o uso social que se faz da leitura e da escrita.

Ao longo de suas pesquisas, Soares (2002, p. 145) traz vários elementos que visam conceituar o letramento e o define como "o estado ou condição de indivíduos ou de grupos sociais de sociedades letradas que exercem efetivamente as práticas sociais de leitura e de escrita participam competentemente de eventos de letramento", ainda para a autora,

o que esta concepção acrescenta às anteriormente citadas é o pressuposto de que indivíduos ou grupos sociais que dominam o uso da leitura e da escrita e, portanto, têm as habilidades e atitudes necessárias para uma participação ativa e competente em situações em que práticas de leitura e/ou de escrita têm uma função essencial, mantêm com os outros e com o mundo que os cerca formas de interação, atitudes, competências discursivas e cognitivas 
que lhes conferem um determinado e diferenciado estado ou condição de inserção em uma sociedade letrada. (SOARES, 2002, p. 147)

Essas práticas são de extrema importância, pois o sujeito letrado é capaz de dominar a leitura e a escrita de forma competente e frequente no campo social. Portanto, pode-se inferir que ser alfabetizado não é condição para que o sujeito seja letrado, ao contrário, ele pode não saber ler e escrever, isto é, ser analfabeto, mas pode fazer uso da leitura e da escrita em seu meio cultural de maneira indireta e ser um sujeito letrado, uma vez que ele se envolve nas práticas sociais de leitura e de escrita que o cercam. Assim, o termo pode ser entendido por meio de duas dimensões, a individual e a social, que ocorre quando se está envolvido com as habilidades de leitura e escrita e com o uso que se faz das habilidades da leitura e da escrita em algum contexto, respectivamente.

Street (2014) propõe "novos letramentos", dissertando sobre o modelo autônomo e o modelo ideológico. O modelo autônomo é assim denominado devido à sua crítica sobre a dicotomia entre a fala e a escrita, e a concepção dominante do letramento, reduzindo-o a um conjunto de capacidades cognitivas, ou ainda as habilidades individuais do sujeito. Já o modelo ideológico é definido como o letramento em suas práticas sociais e concretas. Como aponta Fernandes (2011, p. 45), “a dimensão ideológica de letramento permite olhar para os diferentes letramentos constituídos nos diferentes grupos étnicos e culturais, os quais, em muitos casos, não são reconhecidos ou valorizados”.

Soares (2002, p. 156) ainda ressalta que,

propõe-se o uso do plural letramentos para enfatizar a ideia de que diferentes tecnologias de escrita geram diferentes estados ou condições naqueles que fazem uso dessas tecnologias, em suas práticas de leitura e de escrita: diferentes espaços de escrita e diferentes mecanismos de produção, reprodução e difusão da escrita resultam em diferentes letramentos.

Nesse modelo, a autora enfatiza os múltiplos letramentos, as práticas escolares e não escolares de letramento e as implicações dessas práticas para o ensino. A partir dessa discussão, e utilizando de outros aportes teóricos, busca-se compreender alguns dos múltiplos 
letramentos, com destaque neste trabalho para o letramento digital, o letramento matemático e o letramento matemático digital.

\section{Múltiplos letramentos: um olhar acerca do letramento matemático e do letramento matemático digital}

O termo letramento foi inserido recentemente no contexto da educação, a partir do surgimento de novos fenômenos que precisavam ser nomeados, como já foi ressaltado anteriormente. Nesse viés, Soares (2012) considera que novas palavras surgem a partir de novos fenômenos. Partindo desse pressuposto, compreendemos que, atualmente, as tecnologias digitais estão presentes nas situações cotidianas e assim, consequentemente, direta ou indiretamente, no ambiente escolar. Por isso, pensar em letramento implica entender que, como postula a autora, não existe letramento, mas sim letramentos. Segundo Ribeiro e Coscarelli (2017), o letramento digital diz respeito "às práticas sociais de leitura e produção de textos em ambientes digitais", ou seja, é o uso de textos nos diversos mecanismos digitais que são disponibilizados atualmente. Nesse ambiente, a tela constitui-se como um novo suporte para a leitura e a escrita digital, trazendo mudanças significativas na interação entre quem lê e o texto, ou entre leitor, o texto e o conhecimento.

De modo geral, o letramento digital pode ser compreendido como o uso de práticas sociais de leitura e de escrita por meio de recursos digitais, ou seja, a capacidade que o indivíduo tem de atender as necessidades sociais que envolvem a utilização dos recursos tecnológicos e da leitura e escrita no meio digital, conforme Soares (2002, 2014), Ribeiro e Coscarelli (2017), e outros autores que discutem sobre o tema. O letramento digital surge por meio das modificações causadas pela inserção das tecnologias digitais, o que não exclui as outras práticas de letramento, mas utiliza-se delas para construir significados no meio digital.

Nesse sentido, o letramento digital ${ }^{4}$ está revestido de grande relevância em meio às transformações ocorridas na sociedade, como a expansão das tecnologias da informação e

\footnotetext{
${ }^{4}$ Letramento digital diz respeito às práticas sociais de leitura e produção de textos em ambientes digitais, isto é, ao uso de textos em ambientes propiciados pelo computador ou por dispositivos móveis, tais como celulares e tablets, em plataformas como e-mails, redes sociais na web, entre outras.
} 
comunicação, uma vez que essas tecnologias, associadas à utilização de várias ferramentas e de diversos outros fatores que se interligam neste processo, exigem dos sujeitos novas formas de aprendizagem e dentre as quais está o desenvolvimento de novas habilidades de leitura e de escrita.

Street (2014) considera que o letramento é de caráter múltiplo, então, ao observar a amplitude deste vocábulo e sua complexidade, por estender-se a diferentes áreas, como aponta Soares (2002), busca-se estabelecer uma conceituação a respeito de uma das tantas práticas de letramentos, nomeada como letramento matemático e, posteriormente, visa-se alcançar uma conceituação para um termo ainda pouco discutido nas pesquisas que envolvem a Educação Matemática no cenário brasileiro, denominado como letramento matemático digital.

A Matemática contribui de maneira significativa para aquele que, além de aprender seus conceitos, os colocam em prática no meio social em que vivem e atuam e por isso a escola deve colaborar para valorizar essa função social com as práticas escolares e com as práticas trazidas pelos estudantes à escola. Assim, a situação desencadeadora de aprendizagem $^{5}$ (SDA) desenvolvida no decorrer deste trabalho busca desenvolver conceitos importantes para mediar às relações sociais em que sujeitos estão inseridos.

Ao apoiar-se na perspectiva do letramento ideológico proposto por Street (2014), e utilizando de uma abordagem sociocultural nas quais as práticas de letramento estão pautadas, é possível reconhecer que existe uma multiplicidade de letramentos que, segundo Pellatieri (2013) "ao ser palco para a convivência desta diversidade de letramento, torna-se papel da escola possibilitar aos estudantes transitar e vivenciar estes diferentes letramentos, a fim de dar sentido e fazer uso de forma ética e crítica das diversas práticas sociais de que fazem parte".

A autora ainda salienta que

quando falamos em práticas escolarizadas de letramento não estamos nos referindo apenas ao conceito de letramento autônomo, não estamos considerando apenas as práticas de alfabetização, mas as práticas que são desenvolvidas dentro da escola de forma planejada, sistemática, com sentido

Ser letrado digital implica saber se comunicar em diferentes situações, com propósitos variados, nesses ambientes, para fins pessoais ou profissionais (COSCARELLI; RIBEIRO, verbete, 2014).

${ }^{5}$ Situações desencadeadoras de aprendizagem, baseadas em Vigostski (2009), são situações criadas pelos professores para que o estudante consiga mobilizar conhecimentos na realização das tarefas propostas. 
e que podem ser avaliadas e relacionadas a múltiplas linguagens (PELLATIERI, 2013, p. 31).

Assim, refletir sobre o letramento matemático, relacionado aos mais variados usos sociais da Matemática, é refletir a respeito das práticas escolarizadas de letramento. Nesse sentido, letramento matemático é conceituado por Pellatieri (2013) como a relação entre a Matemática e as práticas diferenciadas que resultam em diversas matemáticas. Desse modo, entende-se que o estudante utiliza suas competências matemáticas ao se deparar com os desafios do futuro. Sendo assim, ele se torna capaz de analisar, julgar e comunicar formulando e resolvendo problemas matemáticos em várias situações, ou seja, compreender o papel que a matemática representa no mundo.

O estudante letrado matematicamente torna-se capaz de realizar julgamentos matemáticos e utilizar a Matemática como forma de satisfazer suas necessidades de forma reflexiva e construtiva. De acordo com Kleiman (1995),

[...] pode-se afirmar que a escola, a mais importante das agências de letramento, preocupa-se não com o letramento, prática social, mas com apenas um tipo de prática de letramento, qual seja, a alfabetização, o processo de aquisição de códigos (alfabético numérico). [...] já outras agências de letramento, como a família, a igreja, a rua - como um lugar de trabalho -, mostram orientações de letramento muito diferentes (KLEIMAN, 1995, p. 20).

As terminologias usadas, no campo da Matemática, para definirem as relações dos conhecimentos matemáticos com as práticas sociais, como aponta Moreira (2015), variam entre numeramento, numeracia e letramento matemático, mas como já mencionado, optou-se por letramento matemático, uma vez que esse pode ser desenvolvido em diversas práticas, dentro e fora da sala de aula, sendo indissociável das práticas de numeramento e das práticas letramentos. Esse aspecto fica enfatizado por Mendes (2007, p. 25), pois segundo a autora,

ao focalizarmos o numeramento, podemos nos reportar às diversas práticas sociais, presentes na sociedade, que moldam os eventos de numeramento em contextos diversos. Na verdade, creio que, talvez, não seja possível 
identificar um evento exclusivamente de numeramento, pois de algum modo à escrita e a leitura podem estar associadas à realização desses eventos. Indo além, as formas de representação escrita nos diversos eventos de numeramento podem ir além da escrita numérica, abarcando outras formas de representação como, por exemplo, a visual (leitura de gráficos, representações geométricas, representações de espaço, etc.). [...] as práticas de numeramento podem ser entendidas a partir de padrões relacionados a crenças, valores, concepções, papéis e atitudes que constituem os eventos e são por eles constituídos.

O conceito de letramento matemático não envolve apenas as práticas sociais de uso da Matemática, mas envolvem também as técnicas, por isso o conceito de letramento não pode ser visto afastado do termo alfabetização. Dentro do ensino da Matemática, a possibilidade de compreensão de ideias como contar, medir, estimar, observar padrões e regularidades, entre outras, permitem que os estudantes sejam levados à uma possível leitura matemática de mundo, bem como a contribuição da Matemática para os processos de alfabetização, e por isso, são chamadas práticas de letramento matemático.

Atualmente, com a inserção das tecnologias digitais no contexto social e educacional, e com o alto índice de pessoas que fazem uso desses recursos, vê-se a necessidade de discutir sobre um termo que ainda é pouco explorado no contexto educacional brasileiro que é o letramento matemático digital, visando uma possível caracterização como forma de compreender, dentro da Educação Matemática, novas práticas sociais de utilização das tecnologias digitais como ferramentas potencializadora nos processos de ensino.

Anteriormente, quando se buscou definir o letramento digital, nos embasamos teoricamente em Soares (2002) e Ribeiro e Coscarelli (2017). Soares (2002, p. 151) define o letramento digital como "certo estado ou condição que adquirem os que se apropriam da nova tecnologia digital e exercem práticas de leitura e de escrita na tela, diferente do estado ou condição - do letramento - dos que exercem práticas de leitura e de escrita no papel".

Ribeiro e Coscarelli (2017), em consonância com Soares (2002), pontuam que o letramento digital diz respeito às práticas sociais de leitura e produção de textos em ambientes digitais, isso é, ao uso de textos em ambientes propiciados pelo computador ou por dispositivos móveis, tais como celulares e tablets e em plataformas como e-mails, redes sociais na web, entre outras. Neste trabalho, quando opta-se por buscar uma construção teórica para o conceito de letramento matemático digital, entende-se que, enquanto o letramento digital apresenta as definições apresentadas, o letramento matemático, pautados 
em Mendes (2007) e Pellatieri (2013) é tido como práticas sociais de leitura e escrita, bem como a capacidade de identificar e compreender o papel da Matemática no mundo moderno visando atender às necessidades do indivíduo no cumprimento de seu papel de cidadão.

Diante do exposto, o que seria pensar em letramento matemático digital?

No ambiente cultural, social, e educacional em que se tem contato nos últimos anos, é impossível não perceber o quanto as tecnologias digitais permitiram que muitas mudanças fossem ocorrendo, sejam elas na forma de se comunicar, expressar, ensinar ou aprender. Nesse sentido, entende-se que as tecnologias digitais exercem grande influência em diversos âmbitos da sociedade e na escola não é diferente.

Sabe-se que os desafios da escola e do professor frente a esses recursos se tornam cada vez mais evidentes, o que torna necessária uma reformulação na forma como se ensina atualmente, para que o professor tenha condições de atender as demandas educacionais que seus estudantes estão submetidos. Devido a isso, é que pensar em práticas de letramento matemático e práticas de letramento matemático digital se tornam tão relevantes para a área da educação.

Buscando subsídios teóricos em Street (2004), com base no modelo autônomo e ideológico de letramento, pode-se vislumbrar uma possível caracterização do conceito como parte do modelo ideológico, pois essa dimensão permite olhar para as diferentes práticas de letramento que são constituídas nas mais diferentes áreas. Para Street (2004, p. 90), "o modelo ideológico, não trata de negar as habilidades técnicas ou os aspectos cognitivos de leitura e escrita, mas as compreende como encapsuladas em totalidades culturais e dentro de estruturas de poder".

Nesse sentido, inicialmente seria necessário pensar em práticas escolares e letradas que façam parte das aulas de Matemática, ou seja, um ensino de Matemática que, utilizandose de recursos digitais, permita que os estudantes possam construir significados para o que se está em processo de aprendizagem e assim, uma possível conceituação para o letramento matemático digital poderia ser práticas matemáticas de leitura e escrita que têm as tecnologias digitais como mediação.

Retomando os modelos de letramento propostos por Street $(2004,2014)$, é interessante pensar que o letramento matemático digital engloba as duas dimensões propostas pelo autor, que foram citadas anteriormente: autônoma e ideológica. A dimensão autônoma está presente nas práticas que valorizam o letramento em si, independe do contexto, ou seja, está mais 
voltada para o que se conhece como alfabetização, como exemplo: as práticas em que a Matemática se faz presente de modo inconsciente. Já a dimensão ideológica permite levar em consideração a relação de poder e as ideologias que fazem parte das práticas sociais, aproximando-se do conceito de letramento matemático digital, como ressalta Fernandes (2011).

$\mathrm{Na}$ busca por tentar definir o letramento matemático digital, embasou-se no conceito de letramento e letramento matemático, uma vez que um ser letrado matematicamente e digitalmente vem a ser aquele que faz uso da Matemática social e culturalmente em meios digitais, ou seja, usando as TIC, que fazem parte da cultura atual, como recurso para a aprendizagem, ou também ser aquele que usa dos meios digitais para fazer Matemática de forma exploratória e investigativa, o que, por sua vez, permite uma compreensão matemática e o desenvolvimento de uma postura do sujeito que contribuam para uma melhor integração social desse sujeito.

Espera-se que, como o surgimento de novas pesquisas, seja possível aprimorar a conceituação do termo letramento matemático digital e que essas surjam de modo com que as práticas desse modelo de letramento sejam discutidas no contexto da pesquisa em Educação Matemática. Nesse sentido, o próximo tópico visa argumentar sobre a inserção das tecnologias digitais no contexto escolar e especificamente nas aulas de Matemática, apresentando a evolução dessa inserção e quais os benefícios e desafios a sua utilização ocasionam para a educação.

\section{A inserção das tecnologias digitais e das mídias: apontamentos teóricos}

Ao longo da história, a produção de conhecimento e, consequentemente, o desenvolvimento humano são marcados pela relação humano-mídia. Entretanto, Borba (2001) elabora a metáfora seres-humanos-com-mídias, postulando que tanto os humanos quanto as mídias são participantes na construção coletiva de conhecimento, ou seja, o pensamento se reorganiza com a presença delas e possibilita assim, a compreensão dos tipos de conhecimentos atingidos por esses coletivos que abrangem seres humanos e mídias. Nos últimos anos, do final do século XX até o presente momento, com o advento das tecnologias 
digitais, a sociedade tem experimentado mudanças de paradigmas, como por exemplo, na maneira e velocidade de se adquirir informações, bem como nas opções de artefatos tecnológicos como elemento mediador da aprendizagem, os quais podem permitir, cada vez mais, uma maior interação do sujeito (estudante) com o seu objeto (conhecimento).

Quando se procura refletir a respeito da relação tecnologia e educação, é possível perceber que existe um distanciamento entre escola e sociedade quando se trata de paradigma de conhecimento. Há um conflito epistemológico, no qual as escolas permanecem experimentando limitadas alterações e, na maioria das vezes, continuam fazendo uso do modelo tradicional de ensino, gerando a preocupação para que a mesma se adeque às transformações da sociedade e, consequentemente, à transformação dos sujeitos que pertencem e frequentam essas escolas. A não adequação acaba gerando um dos conflitos entre escola e tecnologia, uma vez que as mudanças são tidas como um desafio tanto para a instituição quanto para os professores que pertencem à comunidade escolar, por não estarem adaptados, ou até mesmo, preparados para lidarem com os recursos disponíveis na sociedade.

Lévy (1993) enfatiza que as mídias sempre estiveram entrelaçadas com os seres humanos, denominando que as tecnologias da inteligência têm movimentado a vida de todos os sujeitos, especialmente dos educadores, porque essas tecnologias são compreendidas como algo muito mais intenso, já que intervém com o próprio sentido da humanidade. A relação do sujeito com as tecnologias digitais e com as mídias, tornou-se hoje uma relação não mais de dependência, mas uma relação que demanda a aprendizagem dos significados e a interligação dos mesmos.

As tecnologias da inteligência estão associadas à memória e ao conhecimento no qual a oralidade, a escrita e a informática, cada qual ao seu tempo, se tornou extensão da memória. Entretanto, as tecnologias digitais atualmente rompem com a linearidade presente na oralidade e na escrita (BORBA, 2001), uma vez que se passa a ouvir e ver mais através de sons e imagens e a continuidade não mais se faz tão presente na aquisição do conhecimento, pois a tecnologia digital rompe com a continuidade das imagens e textos escritos, tornando-os descontínuos.

Borba (2001) e Tikhomirov (1981) apresentam um posicionamento semelhante no que se refere às tecnologias digitais, uma vez que estabelecem uma relação entre o pensamento e a utilização das técnicas ou tecnologias, afirmando que o computador, ou as tecnologias digitais de um modo geral, não podem substituir os seres humanos, mas possibilitam reorganizar o 


\section{OO DEVIR EDUCAÇÃO}

ISSN: 2526-849X

pensamento de forma que o sujeito se torne capaz de construir o conhecimento com a utilização de alguma mídia.

Para Borba (2001), a posição de Levy (1993) coaduna com a de Tikhomirov (1981), uma vez que ambos propõem que não deve haver oposição entre a técnica e o ser humano. Diante das tais pontuações, pode-se considerar que a tecnologia e sua inserção no ambiente cultural precisam ser analisadas, necessariamente, considerando todos os envolvidos nesse processo e quais as implicações dela na vida dos mesmos.

Com o passar dos anos e o desenvolvimento de novas técnicas, o computador e a tecnologia digital ganham novas definições, como extensão das capacidades cognitivas e, desse modo, essas ferramentas passam a operar com as ideias.

Tikhomirov (1981, p. 4) ainda sustenta que

Será que é suficiente dizer do pensamento verbal humano que ele "opera com sinais" para expressar o aspecto essencial do pensamento? Não, isto não é suficiente. Seguindo Vygotsky, na análise do pensamento verbal eu devo distinguir o sinal por si só, seu referente e seu significado. Ao "operar com sinais", o ser humano opera com significados. Sendo assim, se descrevemos o pensamento humano apenas como manipulação por meio de símbolos, estamos extraindo e focalizando um único e isolado aspecto da atividade pensante de uma pessoa real.

As citações dos autores referenciados sinalizam para a necessidade de compreender que a tecnologia digital e as mídias operam como instrumentos mediadores no ambiente escolar vindo a serem consideradas ferramentas que potencializam os resultados e não apenas uma representação técnica, isto é, atuam em conjunto com o pensamento humano na operação com os significados, tornando assim inevitável a discussão sobre o uso das tecnologias digitais e das mídias nas aulas de Matemática.

\section{As tecnologias nas aulas de matemática}

A Matemática, por vezes, é vista como a disciplina escolar que gera maior apreensão e dificuldades relacionadas à aprendizagem dos estudantes, fato pesquisado na prática das salas 
de aulas ao longo de muito tempo. Ao observar as mudanças propostas, atualmente, para o ensino por meio das reformulações dos currículos, embora ainda não suficiente, as pesquisas desenvolvidas na área servem como base para uma mudança possível nas aulas de Matemática. É possível perceber que a maneira como o um dado conteúdo é explorado pelo professor, ou quais os recursos utilizados dentro do espaço escolar, desde a formação profissional, até as práticas de desenvolvimento dentro da sala de aula, principalmente na área da Matemática, foco deste trabalho, ainda precisa, em alguns casos, serem reformuladas para que seja alcançado um ensino de qualidade.

Uma das preocupações dos estudiosos da área do ensino de Matemática, no presente momento, está focada em relacionar o conteúdo estudado com a realidade do estudante e trazer a realidade para o espaço escolar, de modo que seja permitida uma maior aproximação entre escola e estudante e assim, obter como resultado, uma maior aprendizagem. Isso inclui a utilização das tecnologias digitais e das mídias que estão intrinsicamente ligadas à realidade dos estudantes que frequentam as salas de aulas atualmente.

Borba, Silva e Gadanidis (2015, p. 16) apresentam e discutem a inserção e as fases da tecnologia digital na Educação Matemática, caracterizando-as em quatro momentos e "enfatizando a forma como a sala de aula tem se transformado para incorporar ou impedir a entrada dessas tecnologias", caracterizando também, a velocidade com que as inovações tecnológicas chegam até os usuários destacando a sociedade atual. Os autores apontam ainda que "as dimensões da inovação tecnológica permitem a exploração e o surgimento de cenários alternativos para a educação e, em especial, para o ensino da matemática” (p. 17).

Algumas tecnologias vão sendo apropriadas no contexto da Educação Matemática e apresentam potencialidades no desenvolvimento do pensamento para o processo de significação que o sujeito vai gerar. Assim, os quatro momentos apresentado por Borba, Silva e Gadanidis (2015) podem ser identificados como:

- $1^{\text {a }}$ fase: ocorre por volta de 1980 , momento em que se utilizavam as calculadoras simples e cientificas e já surgiam expressões como TI (tecnologias informáticas) ou tecnologias computacionais, na qual eram usadas quando visava se referir ao computador ou software. A principal característica dessa fase é o uso do LOGO por alguns pesquisadores, que enfatizava a relação entre linguagem e programação e o pensamento matemático. 


\section{DEVIR EDUCAÇÃO}

ISSN: 2526-849X

- $2^{\mathrm{a}}$ fase: teve início com a popularização do uso de computadores pessoais, por volta da década de 1990, momento em que vários softwares educacionais foram produzidos e programas de formação continuada foram surgindo com o intuito de preparar os professores para fazerem uso dessa nova tecnologia digital. Nessa fase, destaca-se o software de geometria dinâmica e os softwares gráficos.

- $3^{\mathrm{a}}$ fase: surgiu em 1999, aproximadamente, com o advento da internet, que começou a ser utilizada como fonte de informações e meio de comunicação entre professores e estudantes, entre outras funções. Nesse período, consolidaram-se as expressões tecnologias da informação e tecnologias da informação e comunicação (TIC). Destacase também o software Winplot.

- $4^{\circ}$ fase: iniciou em meados de 2004 com o advento da internet rápida e perdura até os dias atuais. Nessa fase é possível perceber que várias características quanto ao uso das tecnologias foram aprimoradas, potencializando sua utilização. Nela, destaca-se o GeoGebra, a multimodalidade, os novos designs e tecnologias móveis e portáteis, entre outras mudanças que ocorrem diariamente visando melhorar e aperfeiçoar as TIC, principalmente no que se referem às tecnologias relacionadas à educação.

Percebe-se que muitas são as formas de inserir as tecnologias digitais e as mídias no contexto escolar, e essas passaram por muitas evoluções até os dias atuais. O que deixa a desejar, muitas vezes, é a forma como ela é inserida, a intencionalidade, os objetivos e a maneira como o professor faz uso dessas ferramentas. Nesse sentido, os mesmos autores citados, concluem que

tentamos ver a tecnologia como uma marca do nosso tempo, que constrói e é construída pelo ser humano. A noção de seres-humanos-com-mídia tenta enfatizar que vivemos sempre em conjunto de humanos e que somos frutos de um momento histórico, que tem as tecnologias historicamente definidas como copartícipes dessa busca pela educação. As tecnologias digitais são parte do processo de educação do ser humano, e também partes constituintes da incompletude e da superação dessa incompletude ontológica do ser humano. (BORBA; SILVA; GADANIDIS, 2015, p. 133)

Nesse viés, a utilização das Tecnologias Digitais de Informação e Comunicação (TDIC), bem como de outros recursos tecnológicos nas aulas de Matemática, como a calculadora, podem vir a possibilitar alterações na forma de ensinar e aprender no contexto da 
sala de aula. Por isso, os professores precisam conhecer as potencialidades e os limites da tecnologia, bem como devem ser preparados para usá-las como mediadoras no processo de ensino, mediante um planejamento cuidadoso que a traga para o contexto da sala de aula. Portanto, faz-se necessário superar os desafios existentes em relação à inserção das TDIC, sejam profissionais, sejam locais, visando à utilização da mesma como uma ferramenta potencializadora da aprendizagem nos ambientes educacionais.

No entanto, entender as fases das tecnologias digitais na Educação Matemática, faz com que seja possível compreender as potencialidades desenvolvidas com a utilização das tecnologias digitais, uma vez que, à medida que elas avançam novos conhecimentos podem ser explorados visando o desenvolvimento do estudante.

\section{Caminhos metodológicos}

A preocupação com o ensino de Matemática tem norteado as pesquisas realizadas nos últimos anos, tanto nos anos iniciais do Ensino Fundamental quanto em todas as etapas da educação, o que, por vezes, justifica-se pela complexidade da linguagem e dos conceitos matemáticos e pelas dificuldades apresentadas por alunos e por professores em relação à disciplina. A mesma preocupação motivou esta pesquisa, mas com enfoque no desenvolvimento do pensamento algébrico mediado por tecnologias digitais nos anos iniciais.

Nesse sentido, o trabalho empreendido trata-se de uma pesquisa de natureza qualitativa, definida como "de particular relevância ao estudo das relações sociais devido à pluralização das esferas de vida" (BOGDAN; BIKLEN, 1994, p. 20).

O material completo, elaborado para a pesquisa realizada no mestrado, está organizado em quatro momentos compostos por nove situações desencadeadoras de aprendizagem (SDA) utilizadas como objeto de investigação. A elaboração dessas SDA se deu a partir de uma revisão bibliográfica que buscou compreender quais as características do pensamento algébrico poderiam potencializar o desenvolvimento de práticas de letramento matemático. A experiência socializada nesse artigo, advém das significações produzidas e analisadas em uma dessas SDA, realizada no espaço da sala de aula e no laboratório de informática da escola, que funciona também como sala de atendimento educacional especializado (AEE). 
No desenvolvimento das SDA, os estudantes foram organizados em grupos com

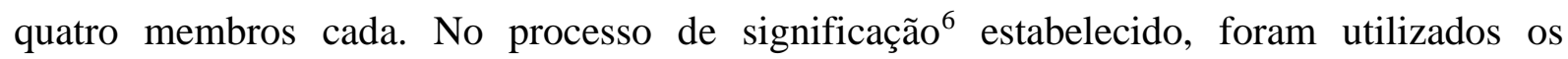
seguintes instrumentos para a produção dos dados: diário de campo da pesquisadora, gravações de áudio e vídeo nas quais se utilizou recursos de gravação de tela nas tarefas realizadas com uso do computador, além de registros fotográficos e escritos do que foi produzido pelos estudantes.

Participaram da pesquisa vinte e quatro estudantes com faixa etária entre dez e onze anos, do $5^{\circ}$ ano do Ensino Fundamental, pertencentes a uma escola pública da rede estadual de ensino, localizada no interior de Minas Gerais, que atende a crianças e adolescentes até o final do Ensino Fundamental. Neste artigo, destaca-se a análise de um dos grupos participantes e preza-se pela preservação de suas imagens.

\section{Uma experiência com o uso do SuperLogo: a prática em sala de aula}

$\mathrm{Na}$ intenção de desenvolver a noção de variável e outras características do pensamento algébrico, bem como explorar a noção de letramento matemático digital, foram propostas SDA, e selecionada uma delas para análise neste texto, em que se utilizou do ambiente Logo de aprendizagem (linguagem computacional Logo) como instrumento de mediação no processo de desenvolvimento do estudante. Ao fazer uso desse ambiente, a criança está ao mesmo tempo lidando com a linguagem escrita e com os conceitos matemáticos.

Dentre os $\operatorname{signos}^{7}$ apontados por Vigotski na perspectiva histórico-cultural, a linguagem escrita é de grande relevância no papel de elemento de mediação, uma vez que ela deve ter significado para o estudante e deve também contribuir no processo de significação, despertando nos estudantes uma necessidade, ou seja, eles precisam compreender a relevância das mesmas.

\footnotetext{
${ }^{6}$ Cabe destacar que o processo de significação envolve os sentidos e os significados e é um processo que independe da indicação ou nomeação do objeto. A inter-relação entre sentidos e significados constitui-se como unidade dialética e é denominada de processo de significação (Vygotsky, 2009).

${ }^{7}$ Vigotski (2009) denomina os signos como instrumentos psicológicos, pois uma vez que os instrumentos têm a capacidade de auxiliar nas ações concretas, os signos tem a capacidade de auxiliar nas atividades psíquicas, e surgem através da necessidade de solucionar problemas psicológicos e assim, controlar suas ações.
} 
Nesse sentido, o Logo atuou como instrumento de mediação entre o processo de significação, ao qual ele é constituído pela tartaruga, animal cibernético, que habita na tela do computador e obedece aos comandos que são expressos, mediante a linguagem específica do ambiente funcionando como um elemento entre o abstrato e o concreto, uma vez que a tartaruga pode ser manipulada. Porém, essa manipulação se dá através dos signos, nesse caso, a linguagem escrita.

Isso fica evidenciado na discussão do quadro 1 em que os estudantes foram convidados a utilizarem o comando repita para manipular a tartaruga, de forma que a tartaruga construísse desenhos, por meio da generalização de um padrão de comandos, mas ao mesmo tempo, é possível perceber que eles os estudantes ainda não haviam consolidado o pensamento, pois realizam tentativas sem utilizar o comando correto mais adequado para aquela situação de generalização do pensamento.

Quadro 1: Discussão sobre o comando repita no Logo - Lavras - 2018.

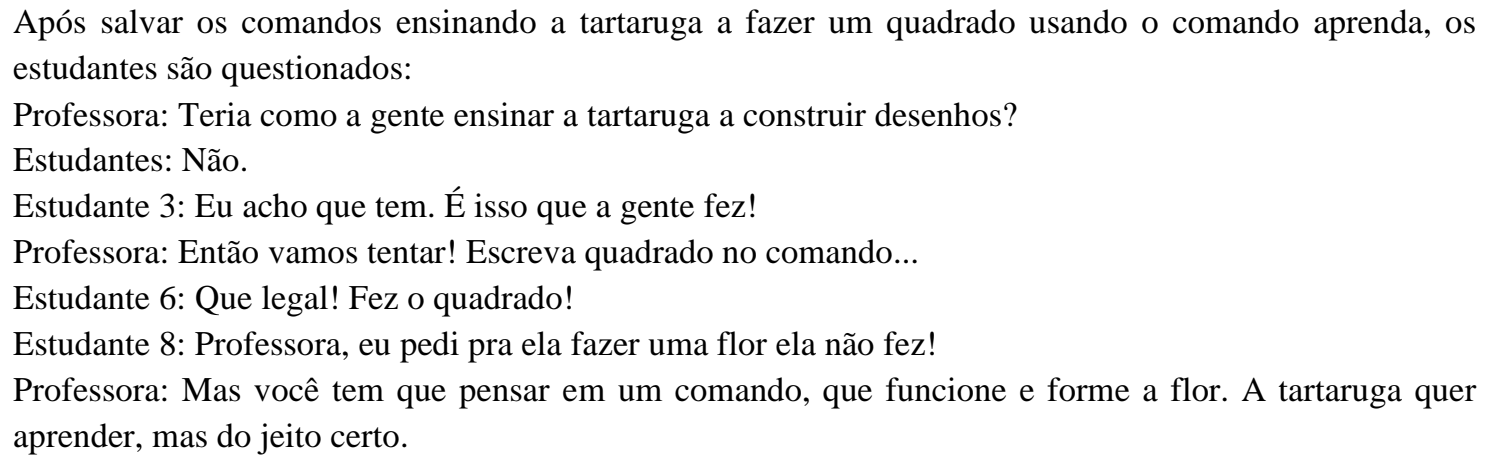

"Os estudantes recebem os comandos, usando o comando repita, para que construam outras figuras. Após um tempo, eles recebem um comando para aprender a fazer uma estrela. (Gritos). A sala vibra quando consegue fazer uma estrela usando o comando repita.” (Diário de campo da pesquisadora)

Fonte: Do autor (2018).

Ensinar a tartaruga os comandos necessários exige dos estudantes conhecimentos socialmente construídos, o que torna pertinente a discussão a respeito do letramento matemático, ou seja, de o estudante ser capaz de fazer uso de seus conhecimentos matemáticos em diversas situações. Quando o estudante questiona a professora a respeito de 


\section{OO DEVIR EDUCAÇÃO}

ISSN: 2526-849X

não conseguir fazer uma estrela usando o comando repita, evidencia-se que, embora ele tenha conseguido realizar a tarefa, ainda não compreendeu que para isso precisaria utilizar comandos que pudessem tornar a programação mais sintetizada.

No entanto, para a construção dessa figura seriam necessários alguns conhecimentos matemáticos e sociais que tornassem o desenho possível, como por exemplo, saber quantas partes compõe a estrela, quais movimentos a tartaruga precisaria fazer e quais os valores que deveriam ser utilizados para que a medida de todas as partes fossem iguais. Embora a tartaruga do ambiente Logo seja um recurso tecnológico, ela depende do conhecimento do estudante para conseguir cumprir com o que lhe é solicitado.

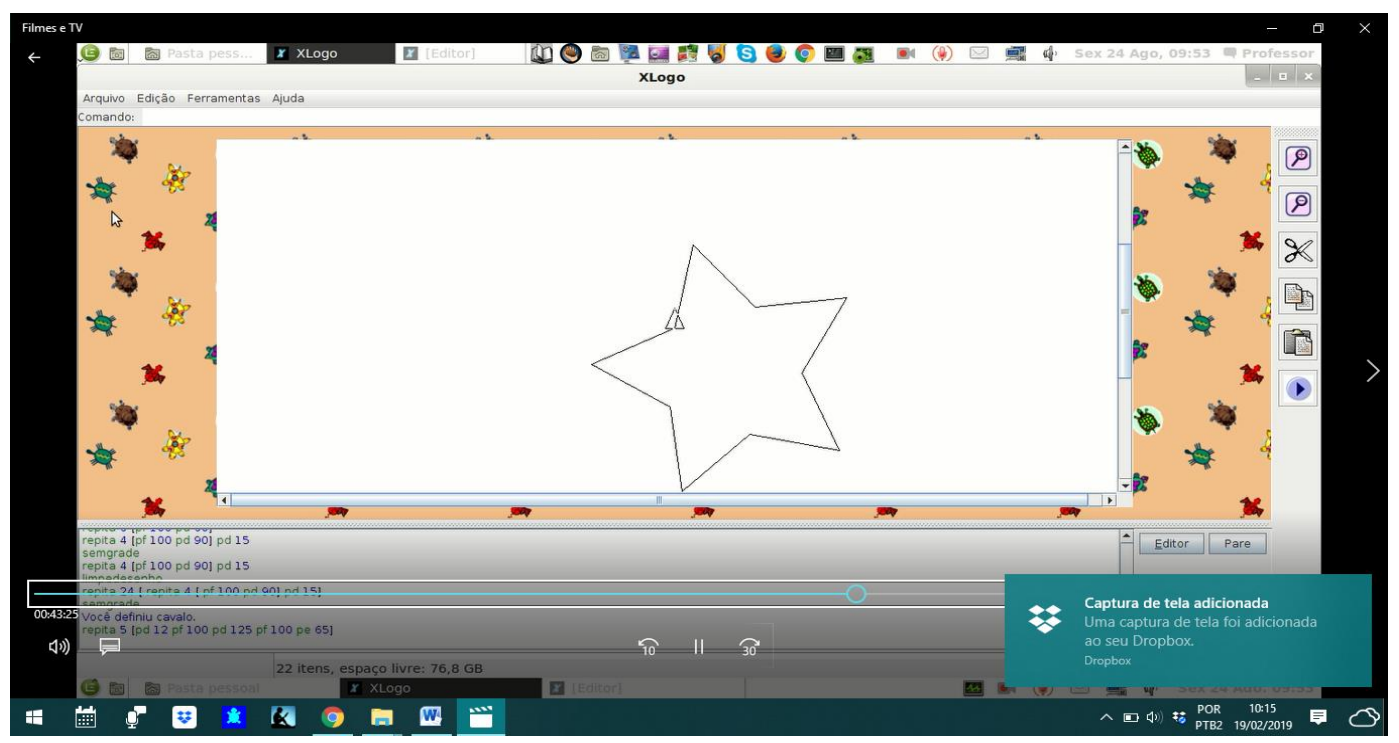

Figura 1: Execução de comandos para formar uma estrela. Fonte: Dados da pesquisa (2018).

Ripper (1993, p. 27) aponta que “o 'tartaruguês', embora se apresente como fala coloquial, é baseada na lógica formal, oferecendo a possibilidade de organizar o pensamento formal num processo similar ao representado pela aquisição da linguagem escrita". Nesse sentido é que está a relevância de utilizar o ambiente Logo como potencializador e mediador do processo de ensino e de aprendizagem dos conceitos matemáticos e, especificamente, os algébricos, pois nessa organização do pensamento é que o estudante entra em atividade em relação às SDA propostas. 


\section{OO DEVIR EDUCAÇÃO}

ISSN: 2526-849X

$\mathrm{Na}$ figura a seguir, o grupo analisado chegou à conclusão de se poderia dar determinados comandos para a tartaruga e depois ir copiando e colando esses mesmos comandos para se obter os movimentos adequados, ou seja, repetindo os comandos era possível construir várias figuras que, devido à repetição, formavam outras de acordo com a posição da tartaruga. Essas ideias preparam para a noção de recursão em Logo, ou seja, a recursão é referente ao processo de repetição e aos ajustes e reajustes realizados durante a ação no Logo, de modo que os estudantes conseguiram produzir uma figura em que pode ser observado um padrão.

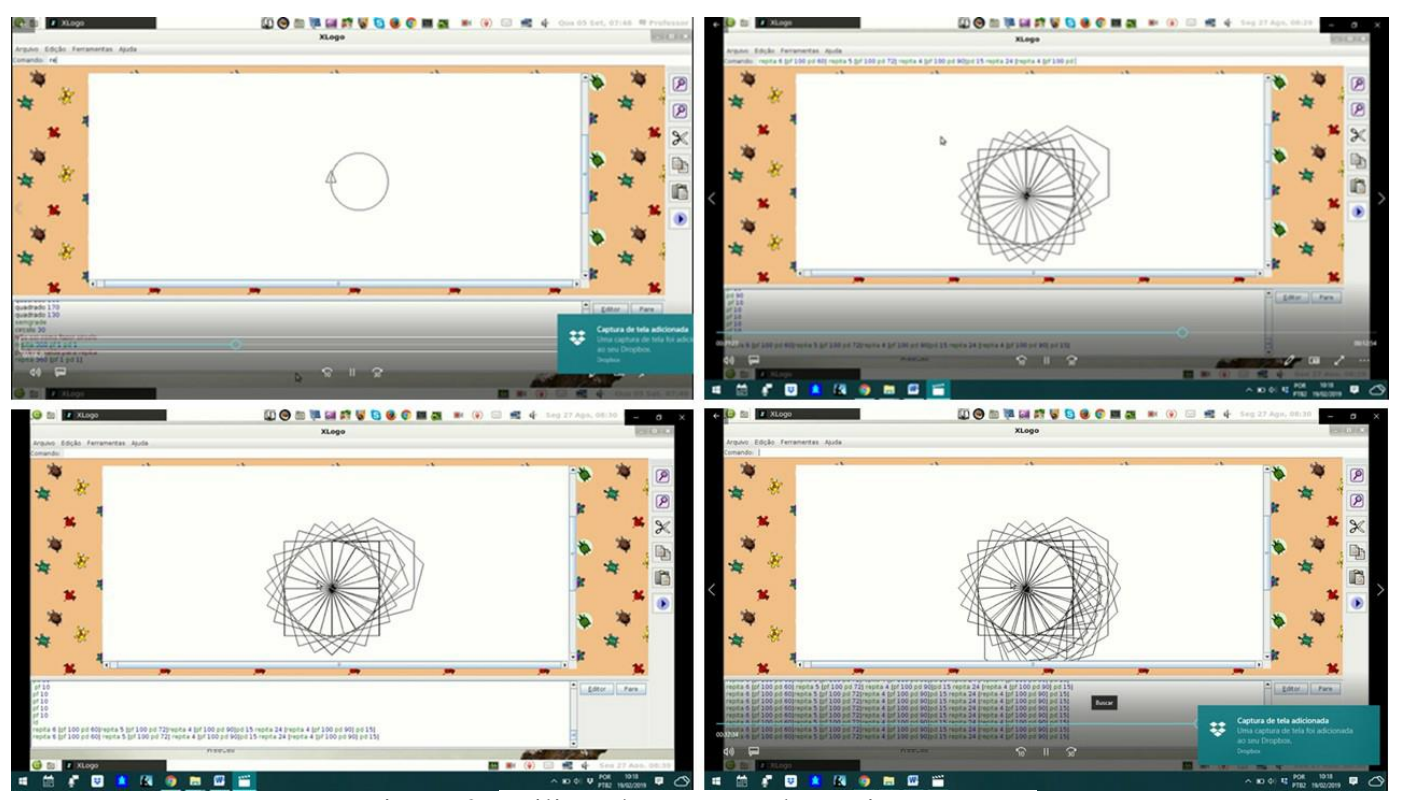

Figura 2: Utilizando o comando copiar no Logo.

Fonte: Dados da pesquisa (2018).

Segundo Amante (2011), o uso das tecnologias digitais nas aulas implica em algumas potencialidades e uma delas é a manipulação de símbolos, ou seja, "há assim a aprendizagem de um dado sistema formal que, tal como na matemática, pressupõe a utilização de um determinado código" (p. 118). Nesse sentido, a utilização do Logo permite que o estudante utilize símbolos capazes de movimentar o ambiente, de forma que atenda as suas necessidades. Para isso, o estudante fará uso de símbolos matemáticos e não matemáticos favorecendo a articulação entre os conteúdos conceituais e procedimentais.

Segundo Leontiev (1978), essa necessidade não se trata de uma necessidade física, mas de uma necessidade de desenvolver as funções psicológicas superiores. No quadro, a 


\section{DEVIR EDUCAÇÃO}

ISSN: 2526-849X

seguir, os estudantes foram questionados sobre a possibilidade de construir formas geométricas no Logo, com medidas variáveis, embora o conceito propriamente dito de variável ainda não faça parte dos conteúdos específicos estudados por eles até essa etapa da educação. Nesse quadro é possível perceber que à medida que os estudantes foram realizando as tarefas propostas, eles foram aprimorando seus conhecimentos. Alguns estudantes começam a compreender que, aliando o pensamento ${ }^{8}$ deles aos comandos, tornavam-se possíveis novas formulações. Retomando ao conceito trazido por Leontiev (1978), por meio da necessidade criada, e da mediação da tecnologia digital, os estudantes entram em atividade para o seu próprio desenvolvimento e para o desenvolvimento do seu objeto, no caso a apreensão do conjunto de conceitos mobilizados na SDA. Segundo Santos (2018, p. 41), “a atividade requer ações que possuam finalidades. Dentro dessas ações ocorrem operações por meio de instrumentos. A necessidade surge no sujeito ou nas relações sociais".

Assim, na utilização do Logo, surge a necessidade de que os estudantes consigam pensar nos comandos corretos a serem apresentados à tartaruga para que ela construa determinada figura.

Quadro 2: Discussão sobre o comando aprender - Lavras - 2018.

Professora: Agora será que seria possível vocês ensinarem a tartaruga a construírem um quadrado com qualquer medida?

Estudante 9: Eu acho que não.

Estudante 2: Tem sim, porque se eu pensar e ensinar a tartaruga ela aprende.

Estudante 1: Mentira.

Fonte: Do autor (2018).

Diante do exposto, compreende-se que o uso das tecnologias digitais potencializa o processo de ensino e de aprendizagem uma vez que o estudante é colocado frente a sua realidade social, pois atualmente a tecnologia digital faz parte do contexto histórico-cultural dos sujeitos e eles fazem uso dessas ferramentas para desenvolverem-se em relação a determinado conteúdo, como é o caso do ensino de Matemática e do desenvolvimento do pensamento algébrico.

\footnotetext{
${ }^{8}$ Utiliza-se o vocábulo pensamento com base nos estudos de Vigotski (2009) e suas reflexões acerca do pensamento abstrato e pensamento concreto.
} 


\section{DEVIR EDUCAÇÃO}

ISSN: 2526-849X

A utilização da tecnologia digital, e de outras mídias, e a intencionalidade em que a SDA foi elaborada, permitiu que fossem desenvolvidas práticas de letramento matemático digital, uma vez que os estudantes mobilizaram conhecimentos cotidianos com os conhecimentos matemáticos e os conhecimentos digitais que eles já possuíam e adquiriram durante a tarefa, e desse modo, conseguiram realizar o que lhes foram propostos.

A experiência em sala de aula contribui diretamente, tanto para a formação do professor pesquisador como para a formação de estudantes que adquiriram relevantes conhecimentos durante o período de observação.

\section{Considerações Finais}

A discussão acerca do letramento matemático digital ainda é recente na área da educação, por esse motivo, embora existam estudos sendo desenvolvidos, ainda não há uma definição clara e precisa sobre o conceito, de modo que são diversos olhares voltados para o assunto, cada qual como sua singularidade.

O presente artigo teve por objetivo analisar as potencialidades do ambiente computacional Logo em práticas de letramento matemático digital no desenvolvimento do pensamento algébrico.

Nesse sentido, discutiu-se sobre o conceito de letramento como uso social da leitura e da escrita e posteriormente sobre o letramento matemático digital e a inserção das tecnologias digitais e outras mídias em aulas de Matemática.

Conclui-se que, para ser letrado matematicamente e digitalmente é necessário fazer uso da Matemática de forma social e cultural em meios digitais, ou seja, usar as TIC, que fazem parte da cultura atual, como recurso para a aprendizagem. Portanto, é também aquele que usa dos meios digitais para fazer Matemática de forma exploratória e investigativa, permitindo assim uma compreensão matemática e o desenvolvimento de uma postura do sujeito que contribuam para uma melhor integração social.

\section{Referências}


BORBA, M,C.(2001). Coletivos seres-humanos-com-mídias e a produção matemática. In: I Simpósio Brasileiro de Psicologia da Educação Matemática. Anais I Simpósio Curitiba, 2001.

Disponível em:<http://www.rc.unesp.br/gpimem/downloads/artigos/borba/borba_coletivos-sereshumanos-com-midias.pdf $>$. Acesso em 12 abr. 2020.

BORBA, Marcelo de Carvalho; SILVA, Ricardo Scucuglia Rodrigues da; GADANIDIS, George. Fases das tecnologias digitais em educação matemática: sala de aula e internet em movimento. 1. ed; 1. reimp. Belo Horizonte: Autêntica, 2015.

COSCARELLI, Carla V.; RIBEIRO, Ana E. Letramento Digital. In: FRADE, Isabel C. A. S.; VAL, Maria G. C.; BREGUNCI, Maria G. C. (Orgs.). Glossário CEALE. Termos de Alfabetização, Leitura e Escrita para Educadores. Centro de Alfabetização, Leitura e Escrita - CEALE. Faculdade de Educação da UFMG. Belo Horizonte: 2014.

FERNANDES, Fernando Luís Pereira. Iniciação a práticas de letramento algébrico em aulas exploratório-investigativas. 2011. 131 f. Dissertação (Mestrado) - Curso de Pósgraduação da Faculdade de Educação, Universidade Estadual de Campinas, Campinas, 2011. Disponível em: <http://repositorio.unicamp.br/bitstream/REPOSIP/251252/1/Fernandes_FernandoLuisPereira _M.pdf>. Acesso em: 18 fev. 2020.

KLEIMAN, Angela Bustos. O que é letramento? In. KLEIMAN, Angela B. (Orgs.). Os significados do letramento: uma nova perspectiva sobre a prática social da escrita. Campinas: Mercado de Letras, 1995.

LEONTIEV, Alexis. Actividad, consciencia y personalidad. Buenos Aires: Ciencias del Hombre, 1978.

LEVY, Pierre. As tecnologias da inteligência: o futuro do pensamento na era da Informática. Rio de Janeiro: Editora 34, 1993.

MENDES, Jackeline Rodrigues. Matemática e práticas sociais: uma discussão na perspectiva do numeramento. In MENDES, Jackeline Rodrigues; GRANDO, Regina Célia. (Orgs.). Múltiplos olhares: matemática e produção de conhecimento. 1 ed. São Paulo: Musa, 2007, p. 11-29.

MOREIRA, Kátia Gabriela. A sala de aula de matemática de um $1^{\circ}$ ano do ensino fundamental: contexto de problematização e produção de significados. 2015. $150 \mathrm{f}$. Dissertação (Mestrado) - Curso de Pós-graduação Stricto Sensu em Educação, Universidade São Francisco, Itatiba, 2015.

PELLATIERI, Mariana. Letramentos matemáticos escolares nos anos iniciais do ensino fundamental. 2013. 126 f. Dissertação (Mestrado) - Curso de Mestrado em Educação, Universidade São Francisco, Itatiba, 2013. Disponível em: <http://www.usf.edu.br/galeria/getImage/385/2781814046174901.pdf>. Acesso em: 12 abr. 2020. 
RIBEIRO, Ana Elisa; COSCARELLI, Carla Viana (Org.). Letramento digital: aspectos sociais e possibilidades pedagógicas. 3. ed. Belo Horizonte: Ceale; Autêntica Editora, 2017.

RIPPER, Afira Vianna. Significação e mediação por signo e instrumento. Temas psicológicos, Ribeirão Preto, v. 1 n. 1, p. 25-30, abr. 1993. Disponível em:<http://pepsic.bvsalud.org/scielo.php?script=sci_arttext\&pid=S1413389X1993000100005\&lng=pt\&nrm=iso >. Acesso em 22 abr. 2020.

SANTOS, Rogério de Souza. O desenvolvimento do pensamento teórico no ensino da termodinâmica em situações desencadeadoras de aprendizagem. 2018. 232 f. Dissertação (Mestrado) - Curso de Pós-graduação em Ensino de Física, Departamento de Ciências Exatas, Universidade Federal de Lavras, Lavras, 2018. Disponível em: <http://repositorio.ufla.br/bitstream/1/30890/1/DISSERTA\%C3\%87\%C3\%83O_O\%20desenv olvimento $\% 20 \mathrm{do} \% 20$ pensamento $\% 20$ te $\% \mathrm{C} 3 \% \mathrm{~B} 3$ rico $\% 20$ no $\% 20$ ensino $\% 20$ da $\% 20$ termodin $\% \mathrm{C} 3 \% \mathrm{~A} 2 \mathrm{mica} \% 20 \mathrm{em} \% 20$ situa $\% \mathrm{C} 3 \% \mathrm{~A} 7 \% \mathrm{C} 3 \% \mathrm{~B} 5 \mathrm{es} \% 20 \mathrm{desencadeadoras} \% 20 \mathrm{de} \% 20$ aprend izagem.pdf >. Acesso em: 15 jan. 2020.

SOARES, Magda. Letramento: um tema em três gêneros. 3. ed. Belo Horizonte, MG: Autêntica, 2016. 124 p.

SOARES, Magda. Alfabetização e letramento. ed. 6. São Paulo: Contexto, 2012.

SOARES, Magda. Novas práticas de leitura e escrita: letramento na cibercultura. In: Educação e Sociedade, Campinas, v. 23, n. 81, dez. 2002. Disponível em: <http://www.scielo.br/pdf/es/v23n81/13935.pdf>. Acesso em: abr. 2020.

STREET, Brian. Los Nuevos Estudios de Literacidad. In: ZAVALA, V.; NIÑO-MURCIA, M.; AMES, P. (eds.). Escritura y sociedad: nuevas perspectivas teóricas y etnográficas. Lima: Red para El Desarrollo de las Ciencias Sociales en el Perú, 2004, p. 81-107.

STREET, Brian. Letramentos sociais: abordagens críticas do letramento no desenvolvimento, na etnografia e na educação. São Paulo: Parábola Editorial, 2014. 240 p. Tradução de: Marcos Bagno.

TIKHOMIROV, Oleg Konstantinovich. The psychological Consequences of Computarization. In Wertsch, J. V. (Ed.). The concept of activity in soviet psychology. New York: M. E. Sharpe Inc. pp. 256- 278, 1981.

VIGOTSKI, Lev Semenovich. A construção do pensamento e da linguagem. 2. ed. São Paulo: WMF Martins Fontes, 2009. (2 tiragem). Tradução: Paulo Bezerra. 